\title{
Adult Neuronal Regeneration Induced by Transgenic Integrin Expression
}

\author{
Maureen L. Condic \\ Department of Neurobiology and Anatomy, University of Utah School of Medicine, Salt Lake City, Utah 84132-0002
}

In a variety of adult CNS injury models, embryonic neurons exhibit superior regenerative performance when compared with adult neurons. It is unknown how young neurons extend axons in the injured adult brain, in which adult neurons fail to regenerate. This study shows that cultured adult neurons do not adapt to conditions that are characteristic of the injured adult CNS: low levels of growth-promoting molecules and the presence of inhibitory proteoglycans. In contrast, young neurons readily adapt to these same conditions, and adaptation is accompanied by an increase in the expression of receptors for growth-promoting molecules (receptors of the integrin family). Surprisingly, the regenerative performance of adult neurons can be restored to that of young neurons by gene transfer-mediated expression of a single $\alpha$-integrin.

Key words: regeneration; intrinsic factors; integrin; inhibitory matrix; chondroitin sulfate proteoglycans; adenovirus-mediated gene transfer
The inability of adult CNS neurons to regenerate is believed to be primarily attributable to the poor environment that the adult CNS provides for neuronal growth. The adult CNS expresses very low levels of growth-promoting matrix molecules and high levels of myelin-associated factors that inhibit the extension of axons (Chen et al., 2000; GrandPre et al., 2000). After injury, there is a pronounced upregulation of inhibitory proteoglycans that are not normally expressed in the mature brain (Hoke and Silver, 1996). In contrast to the characteristically poor regenerative performance of adult neurons in the injured CNS, adult neurons are capable of significant regeneration on permissive substrata (David and Aguayo, 1981; Cheng et al., 1996). Under some conditions, the regeneration of adult neurons can be quite robust [up to $1 \mathrm{~mm} / \mathrm{d}$ in intact (Davies et al., 1997) or degenerating (Davies et al., 1999) white matter]. These results indicate that adult neurons are able to regenerate under some conditions but are severely restricted at the site of lesion by the environment of the adult CNS.

Although the environment of the adult CNS is clearly not optimal for neuronal growth, the CNS environment is unlikely to be the only factor contributing to regenerative failure in the adult. A variety of experimental approaches suggests that there are maturation-associated changes in the inherent ability of adult neurons to regenerate (for review, see Caroni, 1997; Rossi et al., 1997). In contrast to the almost complete regenerative failure observed in the adult CNS, the CNS of embryos is capable of extensive regeneration (Forehand and Farel, 1982; Shimizu et al., 1990; Bates and Stelzner, 1993; Bandtlow and Loschinger, 1997; Wang et al., 1998). When transplanted into the injured adult CNS, embryonic neurons show significant outgrowth in the adult

\footnotetext{
Received Jan. 19, 2001; revised April 2, 2001; accepted April 18, 2001.

This work was supported by National Institutes of Health Grant R01 NS38138. I thank A. Cooke for superb technical assistance, Dr. C. Buck for adenoviral constructs, J.-S. Lee for contributions to preliminary data, and Drs. H. J. Yost and M. L. Vetter for suggestions on the manuscript.

Correspondence should be addressed to Dr. Maureen L. Condic, Department of Neurobiology and Anatomy, University of Utah School of Medicine, 50 North Medical Drive, Salt Lake City, UT 84132-0002. E-mail: maureen.condic@hsc.utah.edu. Copyright (C) 2001 Society for Neuroscience $\quad 0270-6474 / 01 / 214782-07 \$ 15.00 / 0$
}

CNS (Wictorin and Bjorklund, 1992; Nogradi and Vrbova, 1994). These results suggest that there are intrinsic differences in the regenerative capability of adult and young neurons that cannot simply be explained by the poor environment of the adult CNS. Although manipulations designed to improve the environment of the adult CNS have received considerable attention, almost nothing is known about the substantial, cell-autonomous deficit in regeneration exhibited by adult neurons.

Previous studies aimed at improving the regeneration of adult neurons have primarily focused on manipulations designed to improve the environment of the adult CNS. The work presented here takes a complimentary approach, focusing instead on the intrinsic properties of adult neurons. The current results indicate that adult performance is greatly impaired relative to that of young neurons, demonstrating that there are intrinsic, cellautonomous deficits in adult regeneration that are independent of the environment. Surprisingly, restoring adult integrin expression to early postnatal levels restores both the ability of adult neurons to regenerate after injury and their ability to adaptively regulate integrin expression. These results demonstrate that substantial improvement can be made in adult regenerative capability by manipulation of a single gene.

\section{MATERIALS AND METHODS}

Cell culture. Dorsal root ganglia (DRGs) were removed from postnatal day zero (P0) rat pups and adult rats that had been killed by $\mathrm{CO}_{2}$ inhalation. DRGs were incubated in $5 \mathrm{mg} / \mathrm{ml}$ dispase: $1 \mathrm{mg} / \mathrm{ml}$ collagenase (Life Technologies, Grand Island, NY) in calcium/magnesium-free PBS at $37^{\circ} \mathrm{C}$ for $35 \mathrm{~min}$ and dissociated into a single cell suspension by trituration with a glass pipette. Cell suspensions were enriched for neurons by preplating on tissue culture plastic for $3 \mathrm{hr}$ in HEPESbuffered F-12 media containing 10\% fetal bovine serum (Life Technologies), followed by removal of the nonadherent neuronal cells. Adult and P0 neurons were cultured in Neurobasal media (Life Technologies) supplemented as described previously (Brewer et al., 1993) to optimize the growth of adult neurons in culture. All media contained neurotrophic factor-3 (NT-3) (Chemicon, Temecula, CA) and NGF (R \& D Systems, Minneapolis, MN) at $10 \mathrm{ng} / \mathrm{ml}$. Substrata containing aggrecan $(\sim 180$ $\mathrm{ng} / \mathrm{cm}^{2} ; 50 \mu \mathrm{g} / \mathrm{ml}$ applied aggrecan for $1 \mathrm{hr}$ at room temperature; Sigma, St. Louis, MO), high laminin (LM) $\left(\sim 300 \mathrm{ng} / \mathrm{cm}^{2} ; 20 \mu \mathrm{g} / \mathrm{ml}\right.$ applied laminin; Life Technologies), low laminin ( $\sim 30 \mathrm{ng} / \mathrm{cm}^{2} ; 1 \mu \mathrm{g} / \mathrm{ml}$ applied 
laminin), and fibronectin (FN) (20 $\mu \mathrm{g} / \mathrm{ml}$ applied FN; Life Technologies) were prepared as described previously (Condic et al., 1999). Cell viability was confirmed by trypan blue staining and by staining of fixed cultures with 4',6-diamidino-2-phenylindole to identify cells with pyknotic nuclei. Numbers of neurites per cell (see Figs. 1, 3, and 4) were determined as described previously for embryonic chick neurons (Condic et al., 1999) from cultures stained with $\beta$ III tubulin to identify neuronal cells. This method was chosen because it generally provides the most conservative estimate of improved regenerative performance (Bomze et al., 2001). In some cases, total neurite length or the length of the longest neurites was determined from digitized images of $\beta$ III tubulin-stained neurons using NIH Image software.

To compare the growth of early postnatal and adult neurons (Fig. 4), P0 and adult DRG neurons were cultured for $72 \mathrm{hr}$ on substrata containing high levels of laminin. Adult neurons were infected at the onset of the culture with adenovirus expressing either $\alpha_{1}$-integrin or $\beta$-galactosidase ( $\beta$-gal). P0 cultures were uninfected. At the end of the $72 \mathrm{hr}$ period, cultures were chilled to $4^{\circ} \mathrm{C}$, and neurons were removed from the dishes by gentle scraping and replated on substrata containing low levels of laminin (LM1 substrata). Cultures were fixed after $6 \mathrm{hr}$, and the number of neurites per cell and the percentage of cells with neurites were determined for each condition for $\beta$ III tubulin-expressing neuronal cells.

Adenoviral infection and integrin expression. Replication-deficient adenoviral constructs expressing integrin $\alpha$-subunits or $\beta$-galactosidase were obtained from the laboratory of Dr. Clayton Buck (Wistar Institute, Philadelphia, PA). Adenoviral constructs were prepared using standard methods. Briefly, full-length mouse $\alpha_{1}$-integrin, human $\alpha_{5}$-integrin, or $\beta$-galactosidase (as a control) cDNA were cloned into the pAd.CMVlink plasmid under the control of the cytomegalovirus immediate early enhancer-promoter element. NIH 293 cells were cotransfected with linearized pAd.CMV-link plasmid (with insert) and the replicationdeficient sub 360 or dl70001 adenoviral backbone. Recombinant virus was collected from plaques, and the inserts were confirmed by PCR. The virus was subjected to three rounds of plaque purification to ensure that a single recombinant was selected and was then purified by centrifugation on a cesium gradient. The titer of the purified recombinant virus was determined with a plaque assay.

Adult and $\mathrm{P} 0$ neurons were infected overnight at a viral concentration of $8 \times 10^{8} \mathrm{pfu} / \mathrm{ml}$. The virus was removed after $16 \mathrm{hr}$, and neurons were cultured for an additional $48 \mathrm{hr}$ to ensure strong expression of the transgene. Cell-surface expression of the integrin transgene was confirmed by staining live cells with antibodies that specifically recognize mouse/rat $\alpha_{1}$-integrin (PharMingen, San Diego, CA) or human $\alpha_{5^{-}}$ integrin (Chemicon). $\beta$-gal expression was confirmed by antibody staining (5 Prime $\rightarrow 3$ Prime, Boulder, CO) of fixed, Triton X-100-extracted cells. The levels of integrin expressed at the cell surface were determined as described previously (Condic and Letourneau, 1997) by immunoprecipitation of cell-surface-biotinylated protein using an antibody that recognizes both the exogenous (mouse/human) and the endogenous (rat) $\alpha$-subunits (Chemicon), followed by Western blot analysis and detection of biotinylated protein using HRP-conjugated avidin and a chemiluminescent reagent (Pierce, Rockford, IL).

\section{RESULTS}

\section{Adult neurons have intrinsic deficits in regeneration}

Sensory neurons of the DRG are an important component of spinal cord circuitry and a well established model for neuronal regeneration because of the failure of their central processes to regenerate after injury in adult animals. Consistent with the superior regenerative performance of young neurons in the adult CNS, early postnatal rat DRG neurons in culture were able to robustly extend neurites on substrata containing low levels of growth-promoting molecules or inhibitory proteoglycans (Fig. 1). In contrast, the outgrowth of adult neurons is significantly weaker than that of young neurons, even on strongly growth-promoting substrata (Fig. 1, LM20 and FN20). It is important to note that all neurons were routinely cultured in media containing NGF and NT-3 at concentrations that are saturating for the tyrosine kinase A (TrkA) and TrkC receptors. Neurotrophin treatment yields the best improvement in adult neuronal outgrowth of any single a
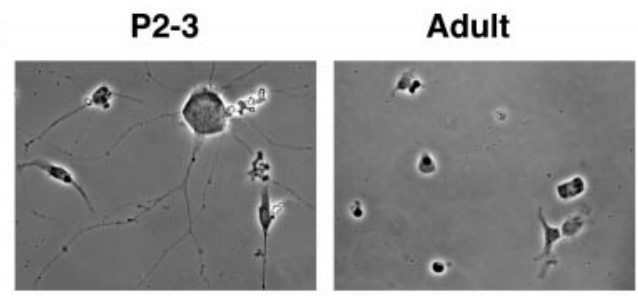

FN1
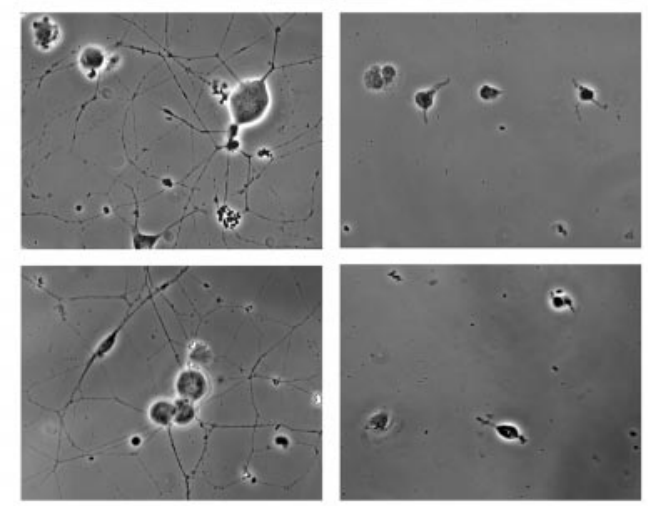

b

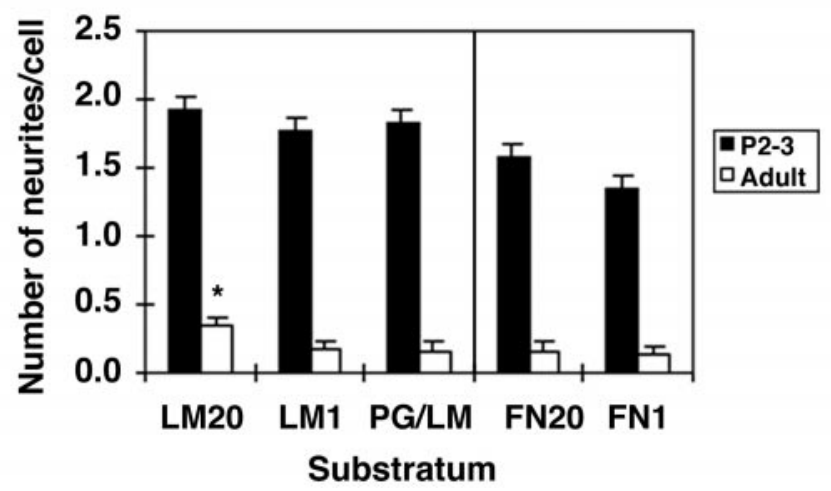

Figure 1. Adult neurons do not extend neurites on weakly growthpromoting or inhibitory substrata. $a$, Phase micrographs of adult and early postnatal (P2-P3) sensory neurons cultured $20 \mathrm{hr}$ on substrata containing low levels of fibronectin (FN1), low levels of laminin (LM1), or the inhibitory proteoglycan aggrecan in combination with high levels of laminin $(P G / L M 20)$. Early postnatal neurons extend numerous neurites on these substrata, whereas adult neurite extension is quite limited. $b$, Early postnatal neurons (solid bars) extend neurites on all substrata tested. Outgrowth of adult neurons (open bars) is poor even on high levels of laminin (LM20) and fibronectin (FN2O) and is further compromised on weakly growth-promoting ( $L M 1, F N 1)$ and proteoglycan-containing $(P G /$ $L M)$ substrata. Data from at least three independent experiments are shown. *Adult outgrowth on LM20 substrata is significantly better than adult outgrowth on either LM1 or PG/LM substrata ( $p<0.025 ; t$ test). All postnatal conditions are significantly different from adults $(p<$ $0.00001 ; t$ test).

manipulation, both in vitro (Mohiuddin et al., 1995; Edstrom et al., 1996; Kimpinski et al., 1997) and in vivo (Schnell et al., 1994; Ramer et al., 2000). Moreover, substrata containing high amounts of laminin (Fig. 1, LM20) are considered to be the optimal substrata for promoting outgrowth of adult neurons in culture. These results indicate that even under optimal growth-promoting conditions in culture, the outgrowth of adult neurons is impaired relative to that of early postnatal neurons (Fig. 1), suggesting that failure of adult neurons to regenerate is partly attributable to the cell-autonomous properties of adult neurons. 
a

$\beta$-gal infected
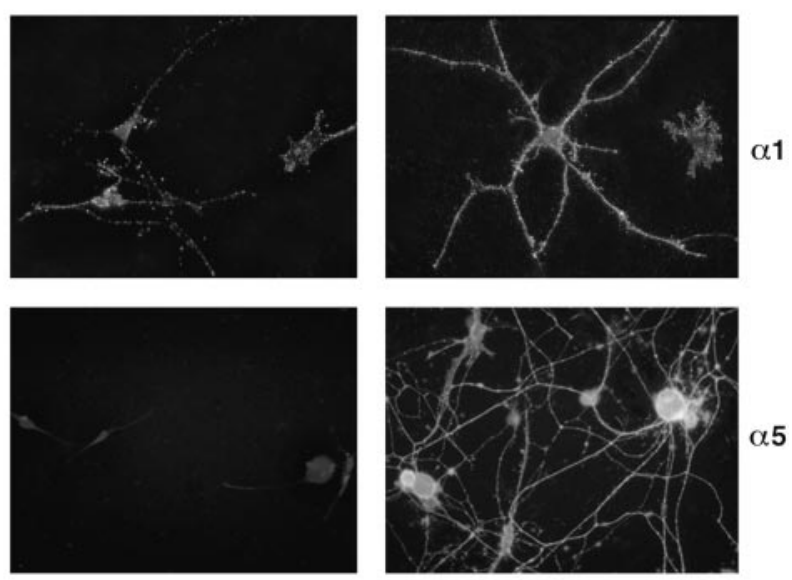

b

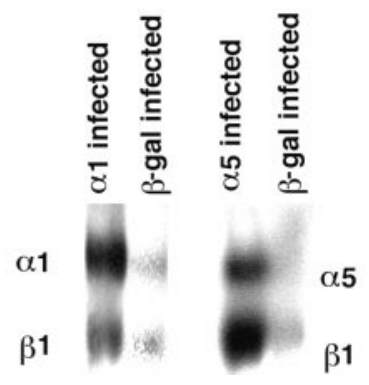

Figure 2. Integrin expression can be increased in adult neurons by adenovirus-mediated gene transfer. $a$, Fluorescent micrographs of adult neurons in culture $72 \mathrm{hr}$ after infection with adenoviral constructs expressing integrin $\alpha$ subunits. Live cultures were stained with antibodies that recognize both the transgenic and endogenous integrin subunit (for $\alpha_{1}$ ) or the transgenic subunit specifically (for $\alpha_{5}$ ). $b$, Western blot analysis of surface integrin protein expressed in adult neurons after infection. Neurons were cultured on low levels of laminin or fibronectin and infected as indicated. Surface-biotinylated protein was immunoprecipitated with antibodies that recognize both endogenous and transgenic integrincontaining receptors. The total surface expression of integrin $\alpha_{1}$ - and $\alpha_{5}$-containing receptors is increased in integrin-infected cells, whereas integrin expression in $\beta$-gal-infected neurons does not respond to weakly growth-promoting substrata and remains low.

\section{Differences in integrin expression and regulation correlate with regenerative performance}

Integrins are the primary receptors mediating axon extension in both embryonic (Letourneau et al., 1994) and adult (Jones, 1996) neurons. Integrin expression is generally high in embryonic and early postnatal neurons and declines to low levels in adult CNS tissue (Jones, 1996; Pinkstaff et al., 1999). The ability of young neurons to extend neurites on diverse substrata (Fig. 1) is quite distinct both from the integrin-dependent migration of nonneuronal cells (Palecek et al., 1997) and from the outgrowth of adult neurons (Fig. 1). In young neurons, high integrin expression supports efficient neurite outgrowth on poorly adhesive substrata (e.g., LM1 or FN1), whereas on strongly adhesive substrata (e.g., LM20 or FN20), a post-translational mechanism allows young neurons to compensate for increased attachment by decreasing integrin expression at the cell surface (Condic and Letourneau, 1997). In contrast, adult neurons showed low levels of integrin expression that were unresponsive to the composition of the substrata (Fig. 2b). Blocking integrin function with antibodies completely prevented attachment of adult neurons to the substratum (data not shown). The low levels of integrins expressed by adult neurons would be predicted to promote neurite extension only when conditions are "optimal" (i.e., when ligand availability is high and inhibitors are absent) (Palecek et al., 1997). In agreement with this prediction, although outgrowth of adult neurons is poor under all conditions, outgrowth on high levels of laminin (for which substratum conditions and integrin expression are well matched) is significantly better than that seen on either low laminin or laminin in the presence of inhibitory proteoglycans (Fig. 1b). Thus, integrin expression in adult neurons is quite low relative to young neurons (Jones, 1996; Pinkstaff et al., 1999), and adult neurons appear to have lost the ability to adaptively upregulate the expression of integrins in response to changes in the composition of the substratum.

\section{Transgenic expression of integrins induces adult regeneration}

The correlation of increased integrin expression with superior neurite extension (Fig. 1) and the previous demonstration that increased integrin expression is sufficient to mediate adaptation of embryonic neurons to inhibitory environments (Condic et al., 1999) suggested that manipulating integrin expression in adult neurons could improve regenerative performance. The decision was made to manipulate the expression of two integrins in adult neurons: integrin $\alpha_{1} \beta_{1}$, the primary laminin receptor in sensory neurons (Tomaselli et al., 1993), and integrin $\alpha_{5} \beta_{1}$, a major fibronectin receptor (Lefcort et al., 1992). Because the $\beta_{1}$-subunit is not limiting, the expression of integrins can be efficiently manipulated in adult (Fig. 2) and embryonic (Condic et al., 1999) neurons by infection with adenovirus expressing full-length integrin $\alpha$ subunits. After adenoviral infection, expression of receptors containing transgenic integrin subunits could be readily detected at the surface of adult neurons (Fig. 2). The overall levels of integrin expressed at the surface of adult neurons were increased (Fig. 2b). The multiplicity of infection was manipulated to yield levels of integrin expression in adult neurons that were comparable with those seen in embryonic and early postnatal rat neurons. This reflected an approximately fourfold increase over the expression seen in uninfected or control-infected adult neurons.

Adult neurons with high levels of integrin expression were tested for adaptation in culture to conditions characteristic of those found in the adult brain after injury. Increased expression of integrins had pronounced effects on the outgrowth of adult neurons in culture (Fig. 3). The effects on outgrowth were specific for the receptor that was overexpressed; e.g., increased expression of integrin $\alpha_{1} \beta_{1}$, a laminin receptor, was associated with increased outgrowth on laminin, but not on fibronectin (Fig. 3). Adaptation was observed both to low levels of growth-promoting molecules and to the presence of inhibitory molecules. Measurements of neurite length were difficult because of the extremely large and complex neuritic arbors observed after manipulation of integrin expression (Fig. 3). However, measurements of neurite length from a representative experiment indicate an even greater level of improvement. For example, the average length of the longest neurite for control neurons on low levels of fibronectin was $233 \pm 31 \mu \mathrm{m}$ (SEM), with an average total neuritic arbor of $489 \pm 79 \mu \mathrm{m}(n=25)$. In contrast, the average longest neurite for adult neurons overexpressing integrin $\alpha_{5} \beta_{1}$ was $900 \pm 67 \mu \mathrm{m}$, with average total neuritic arbor of $4416 \pm 1632 \mu \mathrm{m}(n=17)$. The largest neurons measured in control and $\alpha_{5} \beta_{1}$ integrinoverexpressing conditions had total neuritic arbors of 1575 and 29,612 $\mu \mathrm{m}$, respectively (a $>18$-fold difference). These findings 
a
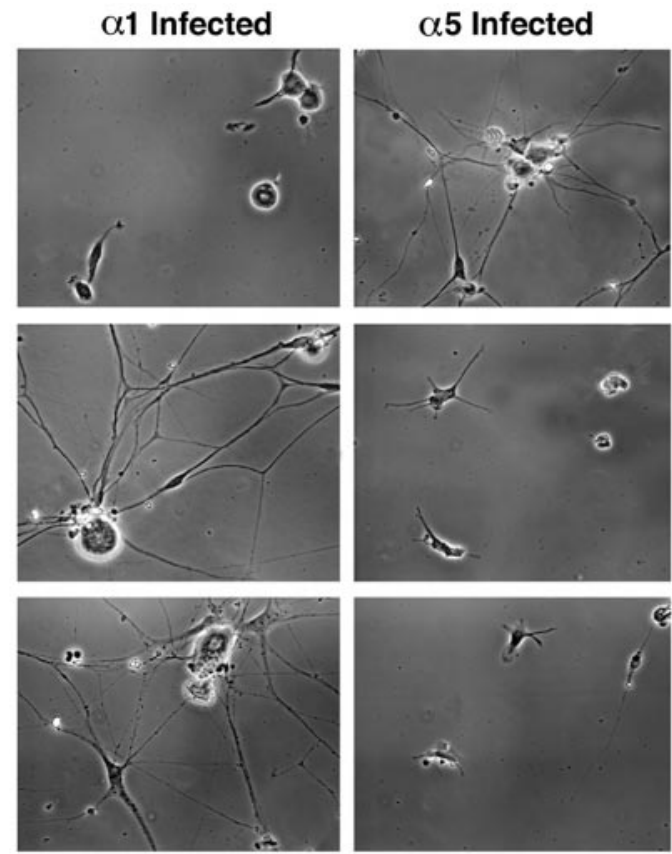

FN 1
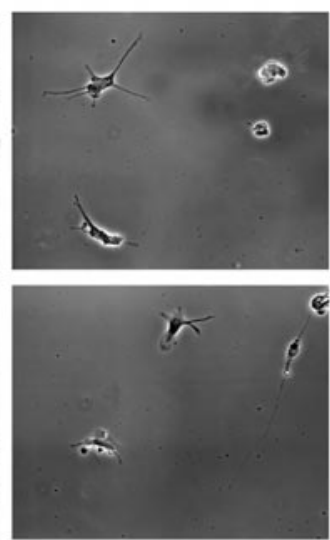

PG/LM

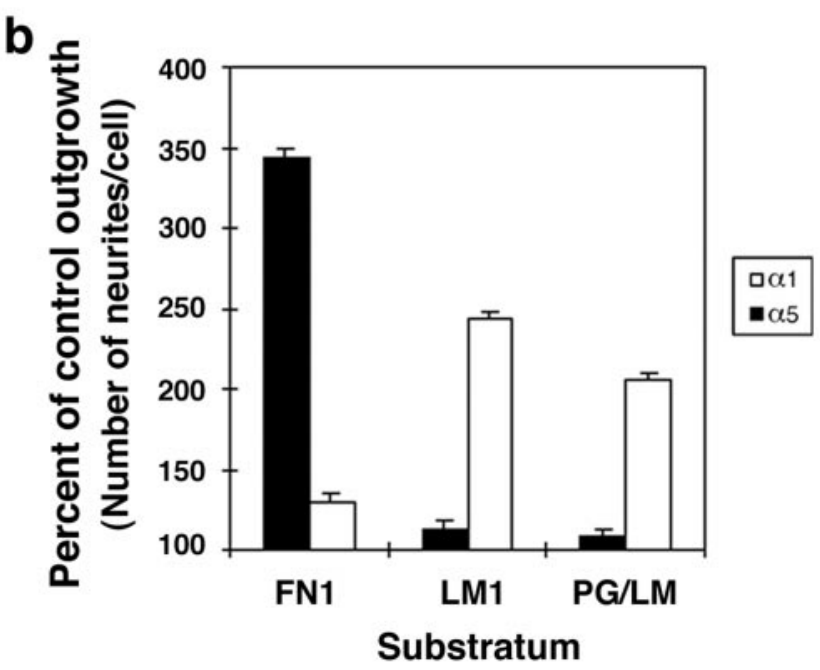

Figure 3. Outgrowth of adult neurons on poor substrata can be greatly improved by increasing integrin expression. $a$, Phase micrographs of adult neurons overexpressing either a laminin receptor $\left(\alpha_{1}\right.$ Infected $)$ or a fibronectin receptor $\left(\alpha_{5}\right.$ Infected $)$. Outgrowth of adult neurons is specifically improved on substrata containing the ligand for the overexpressed receptor. $b$, The growth of integrin-infected neurons as a percentage of increase over controls (infected with $\beta$-gal). Neurons overexpressing $\alpha_{5}$ (solid bars) and $\alpha_{1}$ (open bars) show improved outgrowth specifically on substrata containing ligand for the overexpressed receptor. Data from at least four independent experiments are shown for all conditions. *Significantly different from the other conditions on the same substratum $(p \leq$ $0.0001 ; t$ test).

indicate that increasing integrin expression in adult neurons results in substantial improvement of neurite extension both in the presence of inhibitory molecules and on weakly growthpromoting substrata. Moreover, adult neurons with increased integrin expression showed improved growth when tested on both high and low levels of extracellular matrix ligands compared with $\beta$-gal-expressing neurons (Table 1). This suggests that, similar to early postnatal neurons (Fig. 1), adult neurons with high levels of integrin expression are able to adapt to different substrata by regulating integrin expression.
Table 1. Outgrowth of adult neurons is improved on both strong and weak substrata

\begin{tabular}{lcccc} 
& \multicolumn{4}{l}{ Adult neurons expressing: } \\
\cline { 2 - 5 } Substratum & $\alpha_{1} \beta_{1}$ & $\beta$-gal & $\alpha_{5} \beta_{1}$ & $\beta$-gal \\
\hline LM1 & $1.56 \pm 0.2$ & $0.7 \pm 0.1$ & - & - \\
LM20 & $2.27 \pm 0.3$ & $0.6 \pm 0.1$ & - & - \\
& & & & \\
FN1 & - & - & $1.85 \pm 0.1$ & $0.63 \pm 0.1$ \\
FN20 & - & - & $2.19 \pm 0.1$ & $0.93 \pm 0.2$
\end{tabular}

Adult neurons expressing high levels of the indicated transgene (at $72 \mathrm{hr}$ after infection), replated on the indicated substratum, and the number of neurites per cell determined after overnight culture are shown. The mean and SEM from at least three independent experiments are given. For all conditions, integrin-expressing conditions are significantly different from controls $(p<0.001 ; t$ test).

\section{Improved adult regeneration is comparable with that of young neurons}

Given the very weak outgrowth of unmanipulated adult neurons even on permissive substrata (Fig. 1), the substantial improvement that was observed by increasing integrin expression may still leave the performance of adult neurons significantly inferior to that of young neurons under the same conditions. To better determine the contribution of increased integrin expression to adult neurite extension, the outgrowth of adult neurons expressing high levels of integrin $\alpha_{1} \beta_{1}$ was directly compared with that of early postnatal neurons. I chose to examine the condition for which intermediate improvement of adult outgrowth was observed after manipulation of integrin expression: the outgrowth of neurons on low levels of laminin (Fig. 3b). When young neurons and adult neurons expressing integrin $\alpha_{1} \beta_{1}$ or $\beta$-galactosidase were compared with young neurons, the outgrowth of adult neurons with manipulated integrin expression was indistinguishable from that of early postnatal neurons (Fig. 4). Thus, increasing integrin expression restores neurite extension in adult neurons to the level observed in early postnatal neurons.

\section{DISCUSSION}

These results demonstrate that there are clear, intrinsic differences in regenerative capability between adult and immature neurons. Outgrowth of adult neurons is impaired even under optimal conditions (i.e., high concentrations of laminin in the substratum and saturating concentrations of neurotrophins in the media). Interestingly, this cell-autonomous deficit in adult regeneration is observed in DRG neurons, a population that is clearly capable of peripheral (but not central) regeneration in vivo, indicating that even adult peripheral neurons are significantly compromised relative to their younger counterparts. When integrins are expressed in adult neurons at levels comparable with those seen in young neurons, neurite extension is likewise restored to postnatal levels. This improvement is specific for substrata containing ligands for the manipulated receptor. Moreover, the improvement observed is quite pronounced, representing up to a 2.5-fold improvement in the number of neurites per cell and a 10-fold improvement in neurite lengths compared with controls.

\section{Adaptation of neurons to diverse environments}

For most cell types, integrin-dependent migration occurs only at intermediate levels of cell attachment, because a precise balance between "holding on" and "letting go" can be maintained (Di- 


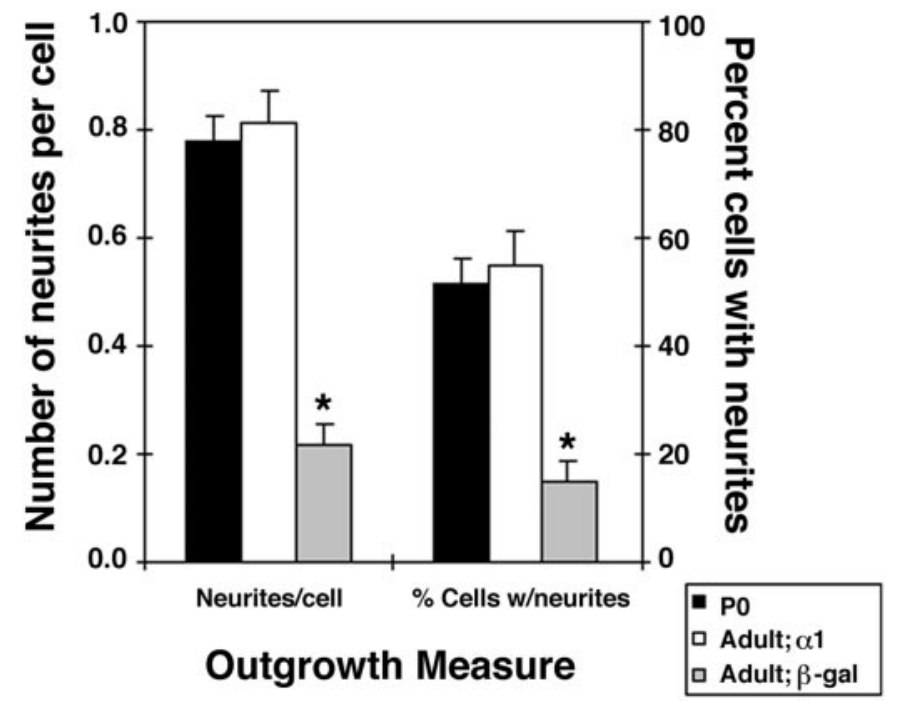

Figure 4. The outgrowth of adult neurons after manipulation of integrin expression is comparable with that of early postnatal neurons. Adult neurons were infected with adenoviral constructs containing integrin $\alpha_{1}$ or $\beta$-galactosidase and were cultured for $72 \mathrm{hr}$ to ensure strong expression of the transgenes. Postnatal day zero rat neurons were cultured in parallel for $72 \mathrm{hr}$ without infection. Neurons were removed from the plates and recultured on LM1 substrata for $6 \mathrm{hr}$. Cultures were fixed, and the number of neurites per cell and the percentage of cells with neurites were determined for at least 100 cells from four independent experiments. *The $\beta$-galactosidase-infected adult neurons are significantly different from both $\mathrm{P} 0$ and $\alpha_{1}$-expressing adult neurons $(p<0.0001 ; t$ test).

Milla et al., 1991, 1993). The strength of cell adhesion is proportionate to integrin-ligand availability and to the level of receptor for that ligand expressed by a particular cell type (Palecek et al., 1997). Consequently, for any given cell type migration is generally limited to optimal conditions in vitro and to a correspondingly small number of tissues in vivo. Embryonic sensory neurons are the only known exception to this general rule. Previous work has shown that embryonic neurons modulate the expression of integrins by two independent mechanisms to compensate for both weakly growth-promoting and inhibitory conditions. The availability of ligand in the substratum determines receptor expression by post-translationally regulating the stability of integrins at the cell surface (Condic and Letourneau, 1997), whereas inhibitory molecules cause an increase in intracellular calcium (Snow et al., 1994) and subsequently a transcriptional upregulation of integrin expression (Condic et al., 1999). Unlike embryonic neurons, adult neurons do not compensate for poor environmental conditions by increasing integrin levels at the cell surface. Thus, the a poor environment (such as the adult CNS) is further exacerbated by low levels of integrin expression in adult neurons that fail to promote strong interactions with the substratum. Increasing integrin expression enables adult neurons to efficiently extend axons in weakly growth-promoting and inhibitory environments by matching high levels of receptor expression to substrata that are only weakly adhesive. Moreover, adult neurons with high integrin expression regain the unusual ability of young neurons to modulate integrin expression and thereby extend neurites under a wide range of environmental conditions. These findings suggest that the absolute level of integrin expression, and not the ability to modulate expression, constitutes the major limiting factor for outgrowth of adult neurons under diverse conditions.

\section{Extrinsic and intrinsic contributions to regenerative failure}

The pioneering work of Aguayo and colleagues demonstrated that adult neurons are capable of regenerating in permissive environments (Richardson et al., 1980; David and Aguayo, 1981), a finding that is consistent with the superior outgrowth observed when adult neurons are cultured under optimal conditions (Fig. 1). Recent results from a number of laboratories also support the conclusion that improving the environment can stimulate adult regeneration (Cheng et al., 1996; Li et al., 1997; Ramon-Cueto et al., 1998). Making the environment of the adult CNS more hospitable, by either supplying trophic support (Schnell et al., 1994), counteracting the effects of inhibitory molecules (Schnell and Schwab, 1993; David et al., 1995; Tatagiba et al., 1997), or proteolytically altering the extracellular matrix (LaMotte et al., 1995; Zuo et al., 1998; Ferguson and Muir, 2000) improves adult regeneration. Under conditions that minimize the normal upregulation of inhibitory proteoglycans that occurs after injury, the regeneration of adult neurons can be quite robust (Davies et al., 1997, 1999). These important studies demonstrate the pivotal role of inhibitory factors in the adult CNS and have been the driving force behind efforts to manipulate the environment of the adult CNS as a means of improving adult regeneration. However, modifying the environment of the CNS to counteract inhibitory molecules or increase expression of growth-promoting molecules is a formidable task, even under well controlled experimental conditions. Altering the CNS environment may also effect the connectivity of undamaged neurons (Kapfhammer et al., 1992; Buffo et al., 2000; Romero et al., 2000), yielding unknown effects on normal CNS function.

The significant, cell-autonomous deficit in adult regeneration demonstrated here suggests that a complimentary approach to improving the environment of the adult CNS would be to manipulate the intrinsic state of the neurons themselves. Previous work has shown that the intrinsic state of adult neurons can be a key factor in CNS regeneration (Neumann and Woolf, 1999). In support of this view, several studies suggest that young neurons regenerate to some extent in adult CNS tissue (Wictorin and Bjorklund, 1992; Nogradi and Vrbova, 1994). However, previous work has not provided a controlled comparison of adult and immature neurons, and direct experimental evidence for an underlying mechanism has been lacking. Several growth-associated molecules are differentially expressed between adult and immature neurons (for review, see Caroni, 1997; Rossi et al., 1997), yet the contribution of specific genes to adult regeneration is often unclear. For example, although GAP-43 expression is associated with regeneration in some adult neurons (Vaudano et al., 1995), many regenerating axons do not express GAP-43 (Schreyer and Skene, 1991; Andersen and Schreyer, 1999). Overexpression of GAP-43 in transgenic animals does not stimulate adult neuronal regeneration (Buffo et al., 1997; Mason et al., 2000), whereas overexpression of GAP-43 in combination with a related growth cone protein, CAP-23, does improve adult performance (Bomze et al., 2001). The current study directly comparing adult and immature neurons demonstrates that cell-autonomous deficits contribute to the poor regeneration of adult neurons. Moreover, this work clearly implicates low levels of integrin expression in adult neurons as a significant factor in the poor performance of adult neurons in culture. Finally, this study indicates that substantial improvement can be made in adult regeneration by a single 
gene manipulation, suggesting a possible route for improving adult performance in vivo.

The relative contribution of the current findings to regeneration of both central and peripheral neurons in vivo has yet to be established. In animal models, transgenic vectors can be targeted to damaged cells by local injection into the site of injury (Lou et al., 1998) or into peripheral ganglia (Zhang et al., 1998), allowing for an experimental assessment of how altered neuronal gene expression impacts on regeneration in vivo. The fact that both central and peripheral adult neurons are capable of regeneration in permissive environments (such as peripheral nerve) but fail to regenerate in the adult CNS strongly increases the potential importance of the current findings. Manipulating integrin expression not only improves regeneration of adult DRG neurons on permissive substrata (Table 1) but also greatly enhances outgrowth in environments that otherwise prevent regeneration (Figs. 3, 4), suggesting that central regeneration of DRG neurons can be promoted without inhibiting (or perhaps even stimulating) regeneration in the periphery. In addition, the major molecular components of this model system have all been implicated in vivo: laminin, fibronectin, and aggrecan are physiological substrata found in the adult CNS after injury (Hoke and Silver, 1996), and integrins play a critical role in the interaction of neurons with each of these molecules (Letourneau et al., 1994; Condic and Letourneau, 1997; Condic et al., 1999). Given the robustness and magnitude of the effect demonstrated here, the current findings are quite likely to be relevant to the behavior of neurons in complex environments.

\section{REFERENCES}

Andersen LB, Schreyer DJ (1999) Constitutive expression of GAP-43 correlates with rapid, but not slow regrowth of injured dorsal root axons in the adult rat. Exp Neurol 155:157-164.

Bandtlow CE, Loschinger J (1997) Developmental changes in neuronal responsiveness to the CNS myelin-associated neurite growth inhibitor NI-35/250. Eur J Neurosci 9:2743-2752.

Bates CA, Stelzner DJ (1993) Extension and regeneration of corticospinal axons after early spinal injury and the maintenance of corticospinal topography. Exp Neurol 123:106-117.

Bomze HM, Bulsara KR, Iskandar BJ, Caroni P, Pate Skene JH (2001) Spinal axon regeneration evoked by replacing two growth cone proteins in adult neurons. Nat Neurosci 4:38-43.

Brewer GJ, Torricelli JR, Evege EK, Price PJ (1993) Optimized survival of hippocampal neurons in B27-supplemented Neurobasal, a new serum-free medium combination. J Neurosci Res 35:567-576.

Buffo A, Holtmaat AJ, Savio T, Verbeek JS, Oberdick J, Oestreicher AB, Gispen WH, Verhaagen J, Rossi F, Strata P (1997) Targeted overexpression of the neurite growth-associated protein B-50/GAP-43 in cerebellar Purkinje cells induces sprouting after axotomy but not axon regeneration into growth-permissive transplants. J Neurosci 17:8778-8791.

Buffo A, Zagrebelsky M, Huber AB, Skerra A, Schwab ME, Strata P, Rossi F (2000) Application of neutralizing antibodies against NI-35/ 250 myelin-associated neurite growth inhibitory proteins to the adult rat cerebellum induces sprouting of uninjured purkinje cell axons. J Neurosci 20:2275-2286.

Caroni P (1997) Intrinsic neuronal determinants that promote axonal sprouting and elongation. BioEssays 19:767-775.

Chen MS, Huber AB, van der Haar ME, Frank M, Schnell L, Spillmann AA, Christ F, Schwab ME (2000) Nogo-A is a myelin-associated neurite outgrowth inhibitor and an antigen for monoclonal antibody IN-1. Nature 403:434-439.

Cheng H, Cao Y, Olson L (1996) Spinal cord repair in adult paraplegic rats: partial restoration of hind limb function. Science 273:510-513.

Condic ML, Letourneau PC (1997) Ligand-induced changes in integrin expression regulate neuronal adhesion and neurite outgrowth. Nature 389:852-856.

Condic ML, Snow DM, Letourneau PC (1999) Embryonic neurons adapt to the inhibitory proteoglycan aggrecan by increasing integrin expression. J Neurosci 19:10036-10043.

David S, Aguayo AJ (1981) Axonal elongation into peripheral nervous system "bridges" after central nervous system injury in adult rats. Science 214:931-933.

David S, Braun PE, Jackson DL, Kottis V, McKerracher L (1995) Lami- nin overrides the inhibitory effects of peripheral nervous system and central nervous system myelin-derived inhibitors of neurite growth. J Neurosci Res 42:594-602.

Davies SJ, Fitch MT, Memberg SP, Hall AK, Raisman G, Silver J (1997) Regeneration of adult axons in white matter tracts of the central nervous system. Nature 390:680-683.

Davies SJ, Goucher DR, Doller C, Silver J (1999) Robust regeneration of adult sensory axons in degenerating white matter of the adult rat spinal cord. J Neurosci 19:5810-5822.

DiMilla PA, Barbee K, Lauffenburger DA (1991) Mathematical model for the effects of adhesion and mechanics on cell migration speed. Biophys J 60:15-37.

DiMilla PA, Stone JA, Quinn JA, Albelda SM, Lauffenburger DA (1993) Maximal migration of human smooth muscle cells on fibronectin and type IV collagen occurs at an intermediate attachment strength. J Cell Biol 122:729-737.

Edstrom A, Ekstrom PA, Tonge D (1996) Axonal outgrowth and neuronal apoptosis in cultured adult mouse dorsal root ganglion preparations: effects of neurotrophins, of inhibition of neurotrophin actions, and of prior axotomy. Neuroscience 75:1165-1174.

Ferguson TA, Muir D (2000) MMP-2 and MMP-9 increase the neuritepromoting potential of schwann cell basal laminae and are upregulated in degenerated nerve. Mol Cell Neurosci 16:157-167.

Forehand CJ, Farel PB (1982) Anatomical and behavioral recovery from the effects of spinal cord transection: dependence on metamorphosis in anuran larvae. J Neurosci 2:654-662.

GrandPre T, Nakamura F, Vartanian T, Strittmatter SM (2000) Identification of the Nogo inhibitor of axon regeneration as a Reticulon protein. Nature 403:439-444.

Hoke A, Silver J (1996) Proteoglycans and other repulsive molecules in glial boundaries during development and regeneration of the nervous system. Prog Brain Res 108:149-163.

Jones LS (1996) Integrins: possible functions in the adult CNS. Trends Neurosci 19:68-72.

Kapfhammer JP, Schwab ME, Schneider GE (1992) Antibody neutralization of neurite growth inhibitors from oligodendrocytes results in expanded pattern of postnatally sprouting retinocollicular axons. J Neurosci 12:2112-2119.

Kimpinski K, Campenot RB, Mearow K (1997) Effects of the neurotrophins nerve growth factor, neurotrophin-3, and brain-derived neurotrophic factor (BDNF) on neurite growth from adult sensory neurons in compartmented cultures. J Neurobiol 33:395-410.

LaMotte CC, Kapadia SE, Arsenault K, Wolfe M (1995) Deafferentation-induced expression of GAP-43, NCAM, and NILE in the adult rat dorsal horn following pronase injection of the sciatic nerve. Somatosens Mot Res 12:71-79.

Lefcort F, Venstrom K, McDonald JA, Reichardt LF (1992) Regulation of expression of fibronectin and its receptor, $\alpha 5 \beta 1$, during development and regeneration of peripheral nerve. Development 116:767-782.

Letourneau PC, Condic ML, Snow DM (1994) Interactions of developing neurons with the extracellular matrix. J Neurosci 14:915-928.

Li Y, Field PM, Raisman G (1997) Repair of adult rat corticospinal tract by transplants of olfactory ensheathing cells. Science 277:2000-2002.

Lou J, Lenke LG, Xu F, O'Brien M (1998) In vivo Bcl-2 oncogene neuronal expression in the rat spinal cord. Spine 23:517-523.

Mason MR, Campbell G, Caroni P, Anderson PN, Lieberman AR (2000) Overexpression of GAP-43 in thalamic projection neurons of transgenic mice does not enable them to regenerate axons through peripheral nerve grafts. Exp Neurol 165:143-152.

Mohiuddin L, Fernandez K, Tomlinson DR, Fernyhough P (1995) Nerve growth factor and neurotrophin-3 enhance neurite outgrowth and up-regulate the levels of messenger RNA for growth-associated protein GAP-43 and T $\alpha 1 \alpha$-tubulin in cultured adult rat sensory neurones. Neurosci Lett 185:20-23.

Neumann S, Woolf CJ (1999) Regeneration of dorsal column fibers into and beyond the lesion site following adult spinal cord injury. Neuron 23:83-91.

Nogradi A, Vrbova G (1994) The use of embryonic spinal cord grafts to replace identified motoneuron pools depleted by a neurotoxic lectin, volkensin. Exp Neurol 129:130-141.

Palecek SP, Loftus JC, Ginsberg MH, Lauffenburger DA, Horwitz AF (1997) Integrin-ligand binding properties govern cell migration speed through cell-substratum adhesiveness. Nature 385:537-540.

Pinkstaff JK, Detterich J, Lynch G, Gall C (1999) Integrin subunit gene expression is regionally differentiated in adult brain. $\mathrm{J}$ Neurosci 19:1541-1556.

Ramer MS, Priestley JV, McMahon SB (2000) Functional regeneration of sensory axons into the adult spinal cord. Nature 403:312-316.

Ramon-Cueto A, Plant GW, Avila J, Bunge MB (1998) Long-distance axonal regeneration in the transected adult rat spinal cord is promoted by olfactory ensheathing glia transplants. J Neurosci 18:3803-3815.

Richardson PM, McGuinness UM, Aguayo AJ (1980) Axons from CNS neurons regenerate into PNS grafts. Nature 284:264-265.

Romero MI, Rangappa N, Li L, Lightfoot E, Garry MG, Smith GM (2000) Extensive sprouting of sensory afferents and hyperalgesia in- 
duced by conditional expression of nerve growth factor in the adult spinal cord. J Neurosci 20:4435-4445.

Rossi F, Bravin M, Buffo A, Fronte M, Savio T, Strata P (1997) Intrinsic properties and environmental factors in the regeneration of adult cerebellar axons. Prog Brain Res 114:283-296.

Schnell L, Schwab ME (1993) Sprouting and regeneration of lesioned corticospinal tract fibres in the adult rat spinal cord. Eur J Neurosci 5:1156-1171.

Schnell L, Schneider R, Kolbeck R, Barde YA, Schwab ME (1994) Neurotrophin-3 enhances sprouting of corticospinal tract during development and after adult spinal cord lesion. Nature 367:170-173.

Schreyer DJ, Skene JH (1991) Fate of GAP-43 in ascending spinal axons of DRG neurons after peripheral nerve injury: delayed accumulation and correlation with regenerative potential. J Neurosci 11:3738-3751.

Shimizu I, Oppenheim RW, O'Brien M, Shneiderman A (1990) Anatomical and functional recovery following spinal cord transection in the chick embryo. J Neurobiol 21:918-937.

Snow DM, Atkinson PB, Hassinger TD, Letourneau PC, Kater SB (1994) Chondroitin sulfate proteoglycan elevates cytoplasmic calcium in DRG neurons. Dev Biol 166:87-100.

Tatagiba M, Brosamle C, Schwab ME (1997) Regeneration of injured axons in the adult mammalian central nervous system. Neurosurgery 40:541-546.

Tomaselli KJ, Doherty P, Emmett CJ, Damsky CH, Walsh FS, Reichardt
LF (1993) Expression of $\beta 1$ integrins in sensory neurons of the dorsal root ganglion and their functions in neurite outgrowth on two laminin isoforms. J Neurosci 13:4880-4888.

Vaudano E, Campbell G, Anderson PN, Davies AP, Woolhead C, Schreyer DJ, Lieberman AR (1995) The effects of a lesion or a peripheral nerve graft on GAP-43 upregulation in the adult rat brain: an in situ hybridization and immunocytochemical study. J Neurosci 15:3594-3611.

Wang XM, Basso DM, Terman JR, Bresnahan JC, Martin GF (1998) Adult opossums (Didelphis virginiana) demonstrate near normal locomotion after spinal cord transection as neonates. Exp Neurol 151:50-69.

Wictorin K, Bjorklund A (1992) Axon outgrowth from grafts of human embryonic spinal cord in the lesioned adult rat spinal cord. NeuroReport 3:1045-1048.

Zhang Y, Dijkhuizen PA, Anderson PN, Lieberman AR, Verhaagen J (1998) NT-3 delivered by an adenoviral vector induces injured dorsal root axons to regenerate into the spinal cord of adult rats. J Neurosci Res 54:554-562.

Zuo J, Ferguson TA, Hernandez YJ, Stetler-Stevenson WG, Muir D (1998) Neuronal matrix metalloproteinase-2 degrades and inactivates a neurite-inhibiting chondroitin sulfate proteoglycan. J Neurosci 18 : $5203-5211$ 